\title{
UM OLHAR EM BUSCA DO BELO QUE CONFORTA:i O OUTRO DIANTE DO CINEMA BRASILEIRO
}

\author{
ON THE COMFORT OF BEAUTY:
}

THE OTHER IN FRONT OF BRAZILIAN CINEMA

\section{UNA MIRADA EN LA BÚSQUEDA DE LO BELLO QUE CONSUELA: EL OUTRO DELANTE DEL CINE BRASILEÑO}

\section{Rosa Maria Bueno Fischer ${ }^{1}$ Ananda Vargas Hilgert ${ }^{2}$}

\section{RESUMO}

Neste artigo, discutimos conexões entre cinema, alteridade e educação, partindo do pressuposto de que o cinema produz algo em nós, ao mesmo tempo em que apostamos na potência de desestabilização permitida pelas narrativas fílmicas. Para tanto, operamos com alguns dados de pesquisa realizada com estudantes estrangeiros, em situação de sala de aula, expostos a uma experiência com filmes produzidos no Brasil. $\mathrm{Na}$ análise dos dados, recorremos a Nietzsche, Deleuze, Julia Kristeva, além de Ismail Xavier, Alain Badiou e Alain Bergala. Buscamos com esses autores articular cinema e produção de pensamento, em torno de elaborações sobre o belo, a narrativa cinematográfica, bem como sobre o tema da alteridade.

PALAVRAS-CHAVE: Cinema. Alteridade. Estudante Estrangeiro.

\begin{abstract}
We present, in this paper, a few connections between cinema, alterity and education. We believe cinema produces something on us and, at the same time, allows for a destabilizing experience. Regarding that, we work with data from a research carried out with foreign students and their experience in a class of Brazilian cinema. The analysis is supported by the works of Nietzsche, Deleuze, Julia Kristeva, Ismail Xavier, Alain Badiou and Alain Bergala. These authors help us link cinema and creative thinking around the concepts of beauty, movie narrative and alterity.
\end{abstract}

KEYWORDS: Cinema. Alterity. Foreign Students.

\section{RESUMEN}

En este artículo, se discuten algunas conexiones entre el cine, alteridad y la educación. Partimos de la suposición de que el cine produce algo en nosotros, mientras en que apostamos en el poder de desestabilización permitido por el cine. Por lo tanto, trabajamos con algunos datos de investigación realizada con estudiantes extranjeros, en situación de clase, expuestos a una experiencia con películas producidas en Brasil. En el análisis de los datos, nos volvemos a Nietzsche, Deleuze, Julia Kristeva, así como Ismail Xavier,

\footnotetext{
${ }^{1}$ Doutora em Educação - Universidade Federal do Rio Grande do Sul (UFRGS) - Porto Alegre, RS - Brasil. Professora do Curso de Pós-Graduação em Educação - Faculdade de Educação - Universidade Federal do Rio Grande do Sul (UFRGS) - Porto Alegre, RS - Brasil. E-mail: rosabfischer@gmail.com.

${ }^{2}$ Doutoranda e Mestre em Educação - Universidade Federal do Rio Grande do Sul (UFRGS) - Porto Alegre, RS Brasil. E-mail: anandavh@gmail.com.
}

Submetido em: 02/11/2016 - Aceito em: 05/04/2017

\section{(C) ETD-Educação Temática Digital Campinas, SP v.19 n.2 p. 316-337 abr./jun. 2017}


DOI: https://doi.org/10.20396/etd.v19i2.8647464

Alain Badiou y Alain Bergala. Con estos autores, articulamos cine y producción de pensamiento, en torno de elaboraciones sobre lo bello, la narrativa cinematográfica, así como sobre el tema de la alteridad.

PALABRAS CLAVE: Cine. Alteridad. Estudiante Extranjero.

\section{INTRODUÇÃO}

O jovem estrangeiro chega ao Brasil e matricula-se numa disciplina sobre o cinema feito neste País. Deseja aprender Língua Portuguesa. Quer saber mais de outra cultura. Diante dos filmes a que assiste, de imediato manifesta um "gosto" e, ao mesmo tempo, um pré-juízo: dá-lhe prazer a narrativa que transita pelos temas do amor e da esperança; aprecia a história que lhe provoca a mais genuína emoção; essa escolha, entretanto, não se separa de uma premissa, tacitamente assumida - a de que os brasileiros fazem filmes violentos e tristes, por vezes difíceis de entender; por isso, o jovem estrangeiro parece manifestar apreço quando essa "verdade" se rompe. Paradoxalmente, na condição de estrangeiro a "escutar" uma nova língua, supomos que ele faz o gesto de buscar a si mesmo nos filmes; parece-lhe insuportável ver, na narrativa ficcional, o horror de cenas "realistas" de pobreza e dor, a linguagem metafórica que remete ao cheiro ruim, às sensações de repulsa e nojo.

Neste texto, partimos do pressuposto de que, sempre, de alguma forma, o cinema produz algo em nós. Apostamos em uma certa potência de desestabilização, de produção de pensamento, permitida pela experiência com o cinema. Considerando especificamente a área da educação, sublinhamos a importância de uma dedicação a práticas didáticas e também a pesquisas, envolvendo cinema e filosofia, para pensar uma urgência de nosso tempo: a educação para a arte e para a sensibilidade, no sentido do convite a uma experiência ético-estética, ou seja, aquela que provoca novas formas de aprender, ensinar, educar, relacionar-se consigo e com os outros. Como nos diz o estudioso Ismail Xavier "o cinema que 'educa' é o cinema que faz pensar" (XAVIER, p. 15, 2008); ou seja, o cinema que coloca em cheque nossas percepções, por vezes já sedimentadas; o cinema que nos convoca a dizer algo, a elaborar um pensamento que possa diferir daquilo que já confortavelmente sabemos. Talvez seja isso, efetivamente, que o cinema nos traga: uma sensibilização, uma experiência de pensamento, diretamente relacionada a uma formação ética, estética, em que estão em jogo questões cruciais e contemporâneas dos debates sobre condição social, etnia e raça, gênero, política, alteridade etc.

Para debater alguns dados de pesquisa aqui referida, recorremos a Nietzsche, Deleuze, Julia Kristeva, também a Ismail Xavier, Alain Badiou e Alain Bergala. Buscamos com esses autores articular cinema e produção de pensamento, em torno de elaborações sobre o belo, a narrativa cinematográfica, bem como sobre o tema da alteridade. Tal discussão 
ganha contornos mais fortes, na medida em que estamos tratando de uma pesquisa em que trazemos dados referentes a jovens universitários estrangeiros, vivendo um período de suas histórias acadêmicas no Brasil, numa situação específica de sala de aula: a de ver e discutir filmes brasileiros.

Algumas perguntas norteiam a discussão feita neste texto: estaríamos, inclusive nós mesmos, tratando as produções audiovisuais de nosso tempo, em particular o cinema, a partir da clássica separação entre os modos apolíneo e dionisíaco de ver a arte e a vida? Os estudantes que participaram da nossa pesquisa estariam manifestando essa oposição, tão bem pensada por Nietzsche? Seriam eles herdeiros do pensamento apolíneo, segundo o qual a busca pelo "belo" corresponderia a esconder sob uma máscara qualquer realidade considerada cruel e violenta? Buscar o belo corresponderia a eleger como boa e desejável a arte destinada a apagar qualquer resto ou sinal de sofrimento?

O culto à beleza, às aparências perfeitas, às marcas que nos aproximariam do divino - deveria, segundo o pensamento grego clássico, de base apolínea, ser perseguido em qualquer obra de arte, em qualquer criação, de modo a oferecer a forma bem-acabada, correspondente, por sua vez, ao próprio prazer de viver, longe da dureza, das feridas e dores da existência. Em suma: estamos falando aqui de uma concepção de arte como instrumento para tornar a vida suportável e, ao mesmo tempo, como meio de fugir ao que se chama de "real".

De outro lado, a concepção dionisíaca da vida e da arte, sobre a qual lemos em Nietzsche, nos fala de um modo grego de "tudo sentir", de tudo deixar-se ver e viver, sem privar-se de qualquer pathos, de qualquer verdade, por mais cruel que esta se apresente a nós. Aqui não interessam máscaras de beleza; a própria beleza não se separa do "real" que sangra, dói e fere. Em $A$ visão dionisíaca do mundo, Nietzsche escreve que o arrebatamento dionisíaco não deixa de considerar uma certa ordenação "apolínea" do mundo, mas na condição de vontade de potência, e cujo meio seria justamente a arte trágica, e a ideia trágica da vida (NIETZSCHE, 2005, p. 24-25)

De qualquer forma, as elaborações de Nietzsche não deixam de apontar que, entre os gregos clássicos, manifestava-se "a oposição entre os dois instintos, as duas pulsões, as duas potências, as duas forças artísticas da natureza - o apolíneo e o dionisíaco - era total." (MACHADO, 1999, p.21). Ora, a célebre discussão nietzschiana é retomada neste nosso texto, porque somos herdeiros das marcas dessa dualidade (semelhante a tantas outras, referidas aos pares ficção/realidade, ideal/real), presente nos modos de apreciar, avaliar e receber obras de arte, criações diversas (como a recepção a um filme); e o fazemos, igualmente, para mais uma vez assumir a crítica tão precisa (e tão preciosa) feita pelo

(c) ETD-Educação Temática Digital Campinas, SP v.19 n.2 $\quad$ p. 316-337 abr./jun. 2017 
filósofo - claramente disposto a negar a dicotomia entre aparência e essência, já que estas seriam inseparáveis, impossíveis de serem vividas uma de cada vez, isoladamente.

Deleuze nos traz ideias semelhantes, justamente em relação ao cinema, abolindo a possibilidade de encontrar uma verdade concreta e real nas narrativas fílmicas: ele defende, por exemplo, a "potência do falso" no cinema, num dos capítulos do seu livro "Imagemtempo". O filósofo faz uma extensa discussão sobre falso e falsário numa narrativa cinematográfica, à qual recorremos aqui, justamente porque Deleuze destaca a relação do pensamento nietzschiano com essa quebra da busca pela verdade, do abandono das dicotomias, para entregar-se à vontade de potência. Uma narrativa, para ele, não pretenderia ser verdadeira ou verídica; deveria se tornar, então, falsificadora. A noção de falso em Deleuze enriquece qualquer debate sobre concepções dicotômicas de mundo, pois esse falso não está em oposição a uma verdade; a potência do falso em Deleuze é abandonar uma busca por verdade e assumir a narrativa falsária como aquela que pode provocar e desestabilizar. Isso tem uma relação direta com a eliminação de oposições metafísicas como a que ocorre entre verdade e aparência - oposições que conduzem a uma vontade exacerbada de buscar a "verdade" em tudo. Para Deleuze (com inspiração em Nietzsche), ao negarmos a possibilidade de encontrar uma única verdade (por exemplo, num filme), rejeitando o mascaramento da realidade por meio do belo, o que resta poderia parecer pouco; mas não o é. O que resta é a vontade de potência, a criação, o devir; restam "os corpos, que são forças", considerando-se potência como "o poder de afetar e ser afetado" (DELEUZE, 2007, p. 170). Em poucas palavras: resta o falso, como impulsionador da criação artística. Haveria uma potência no falso, que nos conduz a nos insurgirmos contra a vontade de verdade como uma vontade moral, segundo escreve Roberto Machado, em "Deleuze, a arte e a filosofia" (MACHADO, 2009).

Quando trazemos para o debate a filosofia de Nietzsche e os estudos de Deleuze sobre o cinema, temos clareza de que não há de forma alguma a possibilidade de afirmar, meramente, que os alunos estariam manifestando, por exemplo, um "modo apolíneo" de ver os filmes. Ou que suas observações não estariam em nada relacionadas ao ato criativo (de um cineasta, por exemplo). Seria frágil demais tal escolha, em termos teóricos e metodológicos. Consideramos, porém, que as diferentes dualidades de pensamento (tal como a que opõe aparência e verdade) têm uma memória, reaparecem aqui e ali, estão marcadas de modo diverso nas culturas mais distintas. Essa discussão foi trazida pelos próprios alunos ao longo das aulas, no decorrer dos debates sobre vários filmes, em especial aqueles citados e analisados neste artigo. Consideramos de suma importância atentar para o que está acontecendo em sala de aula, o que os alunos nos trazem, de que forma eles estão percebendo tais produções, para que possamos pensar com maior complexidade 
possíveis relações entre cinema, educação e alteridade. Afinal, como trabalhamos uma educação do olhar mediada pelo cinema e pela alteridade?

Da mesma forma, consideramos que a dualidade aqui tratada associa-se a tantas outras, que ainda marcam nossos modos de ver a vida e inclusive de tratar temas e práticas educacionais: ficção versus realidade, verdade e invenção, amor e dor, sofrimento e felicidade, violência e harmonia, bondade e maldade. Os depoimentos dos alunos nos fizeram revisitar esses modos dicotômicos de pensar: afinal, se eles surgiram tão intensamente durante os debates em aula, acreditamos que devemos atentar para isso. A potência de desestabilização do cinema, que defendemos aqui, diz respeito a também nos depararmos com nossas formas, por vezes, redutoras, muitas vezes já cristalizadas, de ver a arte e a vida. O cinema e, em especial, a relação criada entre cinema, aluno e professor, pode desestabilizar, pode produzir algo em nós, não apenas porque nos "transforma", mas também porque nos expõe a nós mesmos, nos coloca numa posição a partir da qual expressamos nossos gostos, nossas preferências, nossas lutas com a alteridade, por mais dicotômicas ou "já esculpidas" que elas se mostrem.

Trata-se, em suma, de particularidades de um estudo que se oferece à discussão, por meio deste breve texto, colocando em foco uma das muitas possibilidades de lidar com o cinema na educação. No caso, selecionamos as manifestações de universitários estrangeiros, sobre suas escolhas, sobre as sensações diante de filmes, considerados por eles como "belos". A partir de um olhar cuidadoso sobre os depoimentos, passamos a entender que "gostar do filme belo" coloca em jogo formas específicas de analisar um filme, de se posicionar em sala de aula e de "ser outro" diante do cinema estrangeiro.

Entendemos, igualmente, que se reafirma, nas falas e escritos dos universitários, uma vontade de verdade, amarrada ao julgamento de produções fílmicas e de próprio país que eles visitam - vontade de verdade que os faz classificar as narrativas de cinema em "desejáveis" e "desprezíveis". Estão em jogo, assim, não só formas de relacionar-se com imagens e histórias ficcionais, mas também modos de apontar um certo julgamento moral a respeito de personagens, cenas e até mesmo de um país como um todo. Parecem apagarse, nesse gesto, as possibilidades mais abertas de contato com o olhar daquele que é um "nosso outro".

\section{“ESSE FILME TOCOU O MEU CORAÇÃO”}

Alain Badiou escreve que o cinema "exige o outro"; "é uma nova maneira de fazer existir o outro" (BADIOU, 2004, p. 56, trad. nossa). Certamente, um bom filme, com uma narrativa plena de espaços em branco e que nos põe a pensar (como nos diz Ismail Xavier 
[2008]), convida a uma particular relação com a alteridade; mostra-nos o outro, coloca-nos em contato com o desconhecido. Esse outro, exigido pelo cinema, pode-se dizer que constitui parte inarredável de uma certa experiência ético-estética, tem ligação com o que aqui chamamos de potência do cinema, no sentido de uma narrativa que desestabiliza, provocando-nos a genuína urgência de pensamento.

As elaborações de Badiou sobre o cinema como experimentação filosófica sustentam em grande medida este texto, sobre relações entre cinema, educação e alteridade, em que operamos a partir do recorte da pesquisa que tratou de analisar dados de uma prática pedagógica, vivida durante dois anos, no decorrer das atividades de uma disciplina sobre filmes brasileiros, destinada a alunos estrangeiros ${ }^{3}$, como parte do Programa de Português para Estrangeiros. O Programa funciona como atividade de extensão, pela qual são atendidos alunos de outros países, que estão no Brasil para estudar em um curso de graduação e que, nesse contexto, necessitam de apoio quanto ao aprendizado da Língua Portuguesa.

A variedade de nacionalidades é muito grande, mas o fato é que a grande maioria de alunos com os quais interagimos, em todas as turmas, era de origem chinesa. Vindos de Universidades da China, onde já estudavam português, passaram um ano complementando seus estudos linguísticos no Programa da UFRGS. Assim, é importante ressaltar que se tratava de uma disciplina direcionada para alunos já com um nível alto de conhecimento de Português.

Os dois anos (ou quatro semestres, em 2012 e 2013) de acompanhamento e análise nos proporcionaram muitos dados, diferentes situações de sala de aula, com debates e escrita dos alunos - um conjunto de ações que nos ajudaram a pensar sobre a complexa trama que envolve o ato de ver filmes, pensar sobre eles e discuti-los com estrangeiros. Neste trabalho específico, analisamos algumas produções textuais dos alunos, cenas de sala de aula retiradas do diário de campo e respostas dos alunos a um questionário, aplicado no último dia de aula de cada semestre, especialmente sobre os filmes "Central do Brasil", "Abril Despedaçado", "Edifício Master" e "O Cheiro do Ralo"4. Esses filmes provocaram

\footnotetext{
${ }^{3}$ A disciplina faz parte do Programa de Português para Estrangeiros (PPE), vinculado ao curso de Letras da Universidade Federal do Rio Grande do Sul. Os dados que aparecem neste texto referem-se às atividades realizadas nos anos de 2012 e 2013, sendo cada semestre uma turma diferente, mas, ainda assim, com a presença majoritária de alunos chineses.

${ }^{4}$ Os filmes citados neste artigo são: "Central do Brasil" (direção de Walter Salles, 1998), "Abril Despedaçado" (direção de Walter Salles, 2001), "Edifício Master" (direção de Eduardo Coutinho, 2002), "O Cheiro do Ralo" (direção de Heitor Dhalia, 2006), "O Palhaço" (direção de Selton Mello, 2011), "O Invasor" (direção de Beto Brant, 2002).
}

(c) ETD-Educação Temática Digital Campinas, SP v.19 n.2 $\quad$ p. 316-337 abr./jun. 2017 
entre os alunos vários debates, que se destacaram por colocar em funcionamento, muitas vezes, pensamentos sobre uma certa busca pelo que seria considerado "belo" no cinema. Escolhemos, dentre tantos outros dados, abordar aqui algo que nos pareceu muito importante para a concepção de arte e vida que os alunos expuseram. Para problematizar os dados recolhidos, trabalhamos, especialmente, com Alain Badiou e Julia Kristeva (para pensar as relações entre cinema e alteridade); também nos valemos de Nietzsche e Deleuze (para dar conta da discussão sobre a apreciação do que seria o "real" e o "belo" - diante de um filme "estrangeiro").

Vejamos a seguir a resposta de alguns alunos à pergunta "De qual filme você mais gostou e por quê?", retirada do questionário aplicado a todas as turmas no último dia de aula 5 :

Lu: Eu gostei mais do filme "Central do Brasil". O filme mostra o amor familiar comovente, é o filme que tem menos violência.

Cam: Gostei mais de "Abril Despedaçado". Por que esse filme é muito poético, mas ele também mostra a vida dura no interior do Brasil. Tem menos violência e mais esperança.

Sa: Gostei mais de "Central do Brasil". Este filme tocou o meu coração. A salvação está dentro do próprio coração.

Si: Eu gostei mais de "Central do Brasil" porque este filme é bem diferente com outros filmes brasileiros, cheio de amor entre o menino e a mulher.

Da: Eu gostei mais de "Central do Brasil". Porque o filme foi muito emotivo. A emoção entre a mulher e o menino fez o filme feliz.

Is: Eu gostei mais do "O Palhaço", as imagens no filme são coloridas e as cenas são emocionantes.

Ve: Gostei mais de "Abril Despedaçado". Ritmo lento, sentimento e emoções emocionadas.

\footnotetext{
${ }^{5}$ A pergunta citada foi uma dentre tantas outras que motivaram os debates em sala de aula. Acreditamos que começar uma conversa sobre cinema, especialmente com alunos que nunca estudaram cinema antes, e perguntar do que eles gostam seria uma maneira de "chegar" mais próximo do aluno, de evidenciar a relevância de os estudantes terem um efetivo espaço de fala e escuta. O que os alunos diziam a partir disso era o que motivava novas perguntas, ou a escolha de textos de apoio para a discussão, além de outras questões didáticas relevantes. Vale lembrar que, neste texto, utilizamos uma abreviatura para fazer referência a cada aluno, de modo a preservar identidades, conforme estipulado no termo de consentimento assinado por todos.
} 
Esses trechos foram transcritos diretamente das respostas dos alunos, sem qualquer modificação. Há claramente uma recorrência, no que se refere à justificativa para as escolhas: o filme preferido está sempre associado à emoção, aos sentimentos definidos como bonitos, belos e poéticos. Os alunos que apontaram "Central do Brasil" e "Abril Despedaçado", como seus filmes preferidos, mencionaram sempre o quanto ficaram emocionados com os personagens e com a "beleza" da história. Um dos alunos chegou a ser enfático ao extremo: gostou do filme porque a narrativa lhe propiciou "emoções emocionadas". O mesmo tipo de justificativa apareceu relacionado a outros títulos, como "O Palhaço" e "Edifício Master".

Chamamos a atenção para a importância que os próprios alunos deram aos sentimentos de amor, amizade e emoção, como sendo as características que destacavam aqueles filmes em relação a todos os outros vistos ${ }^{6}$. Em vários momentos, os alunos apontavam o quanto consideravam o cinema brasileiro extremamente violento, mesmo sabendo-se que a experiência concreta daquelas pessoas se reduzia a terem assistido a apenas um ou dois filmes daqui, antes de virem para o Brasil. Temos então um primeiro ponto a destacar, digno de discussão mais intensa: em que medida o cinema pode reverter expectativas e colocar em xeque o que sabemos do "outro"? É disso que fala Alain Badiou, quando insiste em afirmar que o cinema exige o outro?

O fato é que muitos alunos estrangeiros, que participaram das aulas (e da pesquisa), chegavam aqui com ideias pré-concebidas sobre um país que, segundo eles, seria predominantemente violento e perigoso - o que imediatamente os levava a esperar o quanto também o cinema feito no Brasil "retrataria" tal problema. Nossa prosaica experiência didático-pedagógica pode ser pensada com base no que escreve Julia Kristeva, sobre a riqueza de viver a radicalidade do "outro" (um outro explicitamente estrangeiro e um outro que também, de certa forma, nos habita a cada um de nós):

Viver com o outro, com o estrangeiro, confronta-nos com a possibilidade ou não de ser um outro. Não se trata simplesmente, no sentido humanista, de nossa aptidão em aceitar o outro, mas de estar em seu lugar - o que equivale a pensar sobre si e a se fazer outro para si mesmo (KRISTEVA, 1994, p. 21).

As manifestações dos alunos por determinados filmes, a nosso ver, pode e deve ser relacionado às justificativas para a não aceitação de outras narrativas; assim, foi possível

\footnotetext{
${ }^{6}$ As turmas assistiram também a filmes como "Durval Discos" (direção de Anna Muylaert, 2002), "O Som ao redor" (direção de Kleber Mendonça Filho, 2012), "Separações" (direção de Domingos Oliveira, 2002), "Lavoura Arcaica" (direção de Luiz Fernando Carvalho, ano de 2001), "Heleno" (direção de José Henrique Fonseca, 2011), Estômago (direção de Marcos Jorge, 2007), todos de estilos muito variados entre si.
} 
perceber, por exemplo, uma importante ligação entre o fato de haver tanta aceitação e prazer, diante de "Central do Brasil", em função da relevância dos temas da amizade e do amor - e a rejeição do filme "O Cheiro do Ralo", em que, conforme os alunos, existe um personagem perverso, sem qualquer marca de carinho ou demonstração de afeto; entre "O Palhaço", pleno de ternura, e "O Invasor" - filme enfaticamente reprovado, por trazer figuras más, prontas a prejudicar o outro. Tais justificativas de escolha apontam para um elemento-chave na relação entre o espectador e o filme: a emoção vivida por aquele que vê, em completa sintonia com os sentimentos dos personagens. Qualquer elemento que viesse desmanchar a harmonia dos "bons sentimentos" era apontado como negativo. Tudo funcionaria, então, como se "a parte obscura de nós mesmos" - como escreve a psicanalista Elisabeth Roudinesco, fosse completamente esquecida e até bloqueada (ROUDINESCO, 2008). Esse foi o mote para muitas discussões, numa dinâmica de aula que funcionava sempre a partir do que os alunos traziam. Talvez uma das formas de se trabalhar cinema e alteridade na educação seja justamente a abertura de um espaço de escuta atenta ao outro para, a partir disso, questionar e multiplicar aquilo que o jovem estudante nos diz.

Assim, em todos os semestres, o filme "Central do Brasil" foi avaliado como um "filme lindo", especialmente pelo final esperançoso, segundo o qual os personagens mudam para melhor, aprendem a amar, buscam a família. Nessa mesma direção (da emotividade "positiva"), o segundo filme mais citado foi "Abril Despedaçado", narrativa destacada especialmente por tratar do amor entre irmãos (a ponto de levar ao sacrifício pelo outro) além de, igualmente, apresentar um final esperançoso:

Da: No fim do filme, o Tonho fugiu para o mar, ele ganhou a liberdade da sua vida própria. Isso é uma esperança.

Os alunos insistiam em destacar atitudes consideradas dignas, bonitas e admiráveis. Tais avaliações apareceram, com a mesma intensidade, nos trabalhos escritos sobre o documentário "Edifício Master". Nas três turmas em que assistimos ao filme de Eduardo Coutinho, os alunos foram convidados a escolher um dos entrevistados do documentário, e a escrever livremente sobre ele. A entrevistada mais citada foi Alessandra, e a justificativa, para a maioria da turma, ligava-se à admiração pela jovem, por sua coragem e otimismo diante da vida:

Ca: Eu gostei dela porque enquanto ela está contando tudo isso, não parece nem um pouco pessimista, ou como muitas pessoas com um ar escuro. Mesmo assim, dá para entender que a vida dela não é fácil. Não é fácil, mas ela não se acha miserável. Fiquei muito emocionada com isso, percebendo que estou perante uma pessoa forte. Ela nem precisa compaixão, porque é forte de verdade. Eu gostei dela porque ela faz me entender que mesmo que a vida é ruim, a gente aceita e sorri. 
Es: Alessandra, uma guria de 20 anos que ganha a vida fazendo programa. Gosto do jeito que ela fala, otimista e espontânea, ela deve sofrer muito na sua vida, mas não vemos no rosto dela nem um pouco de depressão. Quanto ao trabalho como prostituta, ela não tem vergonha para esconder. Ela é uma guria honesta e corajosa. Espero que ela possa melhorar a vida dela, ter muita sorte e sempre manter o otimismo e o lindo sorriso.

Vi: Eu gostei da entrevistada jovem de vinte anos que faz prostituição. Porque ela tentou falar a verdade sobre ela mesma e ficou muito confiante. Ela estava lutando com a sua vida e tentando fornecer coisas boas para filha dela e família dela, embora precise fazer prostituição para isso. Acho que ela é uma mulher forte.

Além de Alessandra, outros entrevistados também foram citados, sublinhando-se sempre a admiração que sentiram pelo otimismo e o sorriso, a atitude positiva diante dos problemas vividos. Essas características apareciam ligadas a algo que os estudantes classificavam, simplesmente, numa palavra, como "belo". Esse belo não aparece isoladamente: é sempre posto em contraste com a violência, com a criminalidade, com a incapacidade de amar. Esse belo é ressaltado como uma crítica ao que o jovem estrangeiro vê como predominante no Brasil. Esse belo é inclusive a sugestão que os estudantes de tão longe fazem aos cineastas brasileiros: que eles multipliquem obras como "Edifício Master", "Abril Despedaçado" e "Central do Brasil".

Sem a pretensão de julgar as escolhas dos alunos, nem apontar o que seria um suposto "espectador correto", ou o "melhor" modo de analisar um filme - optamos por aqui expor esses dados, pois os consideramos relevantes, particularmente em vista do propósito de discutir as relações entre alteridade e cinema, especialmente a partir dos autores já citados, como Alain Badiou e Julia Kristeva. Na medida em que coletamos uma quantidade muito grande de dados empíricos (nascidos da prática de sala de aula durante dois anos, num trabalho com um total de 70 alunos estrangeiros), entendemos que qualquer recorrência mereceria nossa atenção. Por meio das análises dos filmes citados e de alguns estudos filosóficos e sociológicos aos quais recorremos, insistimos em perguntas como estas, que não estão colocadas aqui para que se tenha delas uma exata e pronta resposta: elas estão aqui postas no sentido de provocarem ainda muitas outras pesquisas e produções de pensamento: como nos relacionamos com o cinema estrangeiro? De que forma estabelecemos certas buscas, vontades e desejos, em relação a um filme? De que forma podemos pensar no cinema como uma possibilidade de complexificar relações de alteridade na educação? Como usufuir do cinema para além do fascínio diante daquilo que narcisicamente desejamos ver - como escreve Roland Barthes no provocante texto "Ao sair do cinema" (2004) -, buscando aquilo que "está a mais", que excede as imagens, e que nos faz delas nos distanciarmos, criativamente?

\section{(C) ETD-Educação Temática Digital Campinas, SP v.19 n.2 p.316-337 abr./jun. 2017}




\section{A ESTRANHEZA REPULSIVA VERSUS A EMOÇÃO QUE CONFORTA}

Tanto o filme "Abril Despedaçado" quanto "Central do Brasil" são construídos com cenas quase sempre "emocionantes", vividas por personagens mobilizados por sentimentos fortes e contrastantes. Ambos os filmes foram dirigidos por Walter Salles, o que se comprova ao comparar o estilo e a construção das duas narrativas. Vejamos um pouco da história e dos personagens dos dois filmes.

Em "Central do Brasil", acompanhamos dois personagens em transição, em momentos de mudança, vividos no encontro entre adulto e criança. Fabiana de Amorim Marcello (2009), a propósito, analisa "Central do Brasil" com foco no encontro entre os personagens Dora e Josué, nas transformações que eles sofrem e na importância da viagem como travessia e mudança, como conhecimento de si e do outro.

O menino Josué sofre uma terrível perda logo no começo do filme: sua mãe morre atropelada, deixando-o sozinho, sem nenhum outro parente ou amigo. Dora, logo na sua primeira aparição, é apresentada como uma mulher rude, "endurecida" e, de certa forma, de má índole, pois sobrevive escrevendo cartas para quem é analfabeto - cartas, aliás, que acaba nunca levando ao correio. Dora vê o menino sozinho e resolve vendê-lo para uma quadrilha de contrabando de crianças, imaginando uma forma de conseguir um dinheiro extra. Apesar do trato rude diante da vida e dos outros, Dora passa a ver-se de forma diferente, a partir do encontro com o menino; imagina-se outra; vai além das maldades que ela mesma achava ser capaz de cometer, e acaba então se transformando. A partir deste momento, os dois estão inevitavelmente juntos, e Dora resolve ajudar Josué a encontrar seu pai.

Os dois viajam juntos, cruzam metade do Brasil em busca da família de Josué; a narrativa se desenvolve em função da travessia vivida pelos dois amigos. Como é comum no estilo roadmovie, ambos conhecem pessoas diferentes pelo caminho, novos encontros movimentam seus sentimentos, o que os coloca em situações de profundo conhecimento a respeito de si próprios. Deparam-se com várias facetas do Brasil, com diferentes manifestações de fé e religião, com pobreza, com tantas cidades pequenas e vazias. Dora e Josué viajam com pouco dinheiro, perdem objetos, choram, brigam muitas vezes, demonstram o quanto são diferentes, vivem relações de dominação um sobre o outro. No entanto, a viagem lhes mostra outras possibilidades de existência, nascidas daquela situação extrema. 
Aos poucos, os dois acabam por se reconhecer em meio à desilusão da vida e do sofrimento, em meio à vegetação agreste, à areia vermelha que marca suas roupas e ao sol intenso que imprime em seus corpos e na imagem uma luminosidade. Aos poucos, Josué vai ao encontro de Dora, aproxima-se dela, senta ao seu lado. Juntos, ao pé de uma imensa rocha sólida, mas sozinhos, de frente para uma chapada infinita, eles ficam em silêncio (MARCELLO, 2009, p. 226).

Depois de tantas mudanças, de tantas buscas e desilusões, Dora e Josué chegam ao destino que buscavam e encontram não o pai de Josué, como desejado, mas os irmãos dele, as pessoas que representavam o que ainda restava da família do menino. Dora percebe que Josué será feliz ali, que aquele é seu lugar; decide então voltar sozinha ao Rio de Janeiro e retomar sua vida. No caminho, escreve uma carta a Josué, que deixou no meio da estrada. 0 final é marcado pela separação dos dois, mas o que o espectador vê é que ambos estão diferentes, ambos carregam um pouco do outro dentro de si: trata-se de um genuíno encontro com a alteridade, um contato radical com o diferente. Os personagens estão plenamente modificados. Viveram, cada um, o que se pode chamar de uma experiência arrebatadora de si próprio.

O final de "Central do Brasil" provoca forte emoção no espectador, pela potência de sentimentos demonstrada na ação dos personagens. Apesar da separação de Dora e Josué, os dois seguem felizes, com um sorriso que se mistura às lágrimas. São esses sentimentos que os alunos ressaltam como sendo "bonitos" - e que os fazem, sem qualquer titubeio, dizer que, sim, gostaram do filme. Viveriam eles (e todos nós) uma experiência catártica, diante do filme, daquelas experiências que nos obrigam a olharmos para nós mesmos, plenamente identificados - no caso de "Central do Brasil" - com a força de viver uma verdadeira travessia?

"Abril Despedaçado" se aproxima ao filme "Central do Brasil" em vários sentidos, o que se relaciona muito ao que os próprios alunos escreveram sobre os filmes a propósito de amor, amizade, transformação de si, esperança. "Abril Despedaçado" também trata de viagem e amizade entre adulto e criança. $O$ filme se passa em uma região desértica do sertão brasileiro e tem como núcleo principal a vida de uma família que sobrevive plantando cana. Tonho, o filho mais velho, tem uma missão: vingar a morte do irmão, assassinado por um dos membros de uma família com a qual possuem uma antiga briga, relacionada à posse de terras. Ao cumprir a vingança, Tonho tem poucos dias de vida, até que a outra família deva também cumprir a tradição de vingar o filho assassinado. Assim como os bois que giram para amassar a cana (e que continuam girando até quando o serviço terminou), as duas famílias estão presas em uma tradição, da qual não conseguem sair. 
Tonho tem um irmão mais novo, sem nome, chamado apenas de Menino. É ele que narra grande parte da história - como o personagem que ainda não parece envolvido naquela roda da tradição amaldiçoada, da qual seus pais fazem parte. Menino fala fazendo poesia: quando não sabe um nome, inventa, cria histórias o tempo inteiro, quer a liberdade do irmão Tonho e parece ser o único a ver os males que o estilo de vida de sua família vem trazendo a todos. Menino analisa as situações, sonha em conhecer o mar, não sabe ler, mas está sempre com um livro que ganhou de presente nas mãos, criando histórias. Ele sabe "ler as imagens". Menino podia ser um personagem de poemas do escritor Manoel de Barros, pois brinca com as palavras como se elas fossem objetos, mistura letra e imagem, imaginação e realidade.

Tonho e Menino conhecem uma dupla de apresentadores de circo, Salustiano e Clara. Os dois irmãos assistem a uma apresentação da dupla e ficam encantados, tanto por terem feito algo proibido e escapado de casa no meio da noite, quanto por entrarem em contato com algo que Ihes parecia mágico e fantástico. Encontravam ali emoções novas, tão distintas do que viviam, na lida com a cana e a rotina de casa. Após cumprir o dever familiar e vingar a morte do irmão, Tonho decide viajar com Salustiano e Clara, deixando Menino sozinho -- feliz, pela coragem do irmão em romper com as tradições.

Tonho sai da sua cidade pela primeira vez na vida, conhece lugares novos, convive com pessoas totalmente diferentes de sua família. Os dois artistas muito têm a mostrar a Tonho, que acaba inclusive se apaixonando por Clara. A viagem de Tonho, porém, é provisória; terminado o tempo de trégua, ele acaba voltando para casa - e assim fecha-se o círculo interminável de vinganças familiares. É nesse momento que Menino mostra ser o grande pensador da história, aquele que parece enxergar tudo de uma perspectiva que ninguém mais vê. Menino se faz passar por Tonho e acaba se sacrificando pelo irmão, sendo inclusive morto no lugar de Tonho, pela família inimiga.

O acontecimento inesperado interrompe o círculo da tradição, força um desvio que parece acordar os personagens de um transe. Percebendo o que aconteceu, Tonho toma a decisão de abandonar a família, sem conversa, sem satisfação, sem brigar com ninguém, apenas começa a caminhar em direção ao portão; e só para quando chega no mar. A última cena é a imagem de Tonho contemplando o mar, lugar tão amado e fantasiado por Menino. Diferentemente do final do filme "Os Incompreendidos", de François Truffaut, o encontro com o mar não se mostra como mais uma indagação e um enfrentamento (para o próprio espectador); o mar desenha e amplia uma visão de esperança e de liberdade para o personagem.

(c) ETD-Educação Temática Digital Campinas, SP v.19 n.2 $\quad$ p. 316-337 abr./jun. 2017 
"Abril Despedaçado" pareceu provocar, assim como "Central do Brasil", sentimentos de esperança nos alunos, e uma aprovação unânime pelo forte amor demonstrado entre irmãos. Apesar de o filme mostrar também uma relação familiar sufocante, cheia de tradições contrárias à liberdade de ação e pensamento, além de uma situação de imensa pobreza - apesar disso, o que os espectadores estrangeiros viram ali foi sobretudo a imagem da beleza. Os dois filmes talvez sejam "belos" justamente pelos contrastes e por mostrarem possibilidades de fuga da pobreza, da dor, da tradição. A melancolia é misturada a momentos de exaltação e inclusive a gargalhadas; o marrom das estradas e das roupas contrasta com cenas de céu azul e bandeiras coloridas.

Como mencionamos anteriormente, tratamos os comentários positivos e enaltecedores dos alunos, aos filmes "Central do Brasil" e "Abril Despedaçado", ao mesmo tempo em que analisamos a radical desaprovação a narrativas como "O Cheiro do Ralo". A exaltação do belo se destaca ainda mais quando o contexto de sala de aula mostrou muitas vezes o quanto os alunos não gostavam de (e até tinham dificuldade de falar sobre) filmes violentos, ou com sentimentos que eles consideravam "feios", "repugnantes".

Pode-se afirmar que uma experiência como essa, de aulas sobre cinema brasileiro para estrangeiros, nos oferece múltiplos elementos, de um contexto bastante específico - o que provoca o pensamento, no sentido de um debate sobre nossa relação com a alteridade, quando mediada pela imagem. Vejamos. Os alunos analisam os filmes, falam de gostos pessoais, conversam com colegas de nacionalidades diferentes das suas, recebem tarefas e orientações de aula de uma professora que também lhes é estrangeira. Nenhuma conversa sobre cinema está desvinculada de todo esse complexo contexto. O que os jovens explicitam sobre os filmes, eles o dizem sobre si mesmos, sobre o Brasil, sobre ser estrangeiro, sobre a descoberta de si e do outro - principalmente sobre os empecilhos e as dificuldades trazidas justamente por essa travessia (a de sair de si).

Ao longo dos quatro semestres, foram muitos os filmes que despertaram comentários sobre não gostar do excesso de violência, ou, melhor ainda, da falta de sentimentos belos, emocionantes, a ausência de personagens empáticos e esperançosos. No entanto, escolhemos aqui, pela quantidade de vezes que foi mencionado e pela intensidade dos debates, os comentários a respeito do filme "O Cheiro do Ralo". No último dia de aula, os estudantes avaliaram a experiência com o cinema brasileiro naquele semestre:

(c) ETD-Educação Temática Digital Campinas, SP v.19 n.2 $\quad$ p. 316-337 abr./jun. 2017 
Flo: Não gostei do "O Cheiro do Ralo". Não gosto da personagem principal nem do roteiro. Acho que a razão principal é que não gosto das cenas nojentas e a perversidade da personagem.

Pa: Não gostei de "O Cheiro do Ralo", ainda que bem feito, é muito nojento, quase vomitei, mexeu com meus sentimentos, com minha sensibilidade.

A aluna Pa foi uma das que mais participou do debate em aula sobre "O Cheiro do Ralo"; reiterou que o personagem era uma pessoa "ruim, muito perverso e nojento" e que provocava raiva nela, não Ihe permitindo gostar daquela narrativa. Ela tentava reconhecer o mérito do filme, considerava que se tratava, de fato, de um filme bem feito, mas não tinha como gostar. O personagem Lourenço, de fato, não despertou quase nenhuma empatia nas turmas: muitos deles afirmaram que a morte dele no fim do filme era merecida. As tentativas de análise passavam sempre pelos sentimentos em relação ao personagem e, também, em relação às suas expectativas diante do cinema brasileiro.

"O Cheiro do Ralo" realmente é um filme muito diferente de "Central do Brasil" e "Abril Despedaçado". O diretor Heitor Dhalia faz uma adaptação do romance homônimo de Lourenço Mutarelli (que inclusive atua no filme) e nos apresenta um personagem cheio de perturbações psicológicas, que comete ações de difícil compreensão, com muita agressividade. Lourenço (o nome do personagem é o mesmo do autor do livro) é dono de uma loja que compra objetos usados, normalmente de pessoas com dificuldade financeira; estas chegam até Lourenço dispostas e vender seus pertences por um preço muito baixo. A posição de exploração e dominação sobre os outros parece agradar Lourenço, que procura ainda piorar a situação, com piadas de mau gosto, além de um modo de agir extremamente rude com elas.

Lourenço almoça todos os dias em uma pequena lanchonete perto do trabalho e é atendido pela mesma garçonete. Ele passa a ter uma obsessão pelo corpo da moça, voltando lá todos os dias. Além desse fetiche, há outro elemento constantemente presente na vida de Lourenço: o cheiro do ralo do banheiro onde trabalha. Sua perturbação com o cheiro é imensa: ele fica preocupado que alguém possa pensar que o cheiro venha dele e, por isso, sempre procura explicar do que se trata. Na complexa relação que mantém com o ralo, primeiro tenta negar sua existência, depois fecha o ralo com quilos de cimento, para finalmente desejar o cheiro e quebrar todo o cimento. O cheiro do ralo é uma metáfora desde o começo, mas não aparece com um significado claro e óbvio; pelo contrário, exige do espectador constantes ressignificações.

Lourenço foi definido por muitos alunos como um personagem estranho. De fato, ele age de formas inusitadas, imprevisíveis. Como espectadores em busca de compreensão do 
personagem colocado à nossa frente, tentamos entender aquela personalidade. O que mais nos oferece pistas são os objetos que Lourenço deseja ou não comprar. Um violino, um autógrafo de um ator famoso, notas antigas de dinheiro, são exemplos de artigos teoricamente valiosos e que seriam, logicamente, boas compras para ele; no entanto, não Ihe despertam o interesse. O objeto mais valioso é um olho, pelo qual paga uma quantia enorme. Lourenço passa a levar esse olho consigo, mostra para todas as pessoas que chegam a seu escritório e cria uma história para ele extremamente significativa: diz que aquele era o olho do seu pai, que morreu na guerra. A figura do pai de Lourenço começa a aparecer cada vez mais e a ganhar importância na construção do personagem. Fica claro que Lourenço não conheceu o pai e que isso o afetou profundamente. Assim, ele passa a "construir" o pai como uma espécie de Frankenstein. Ele tem o olho, depois compra uma perna (uma prótese) e aos poucos vai tecendo a história da guerra com outros elementos, até formar a figura do pai herói que desejava ter.

Lourenço não parece ter amor a nada, explora as pessoas, abusa sexualmente das mulheres, deseja o mau cheiro do ralo. Dizer, então, que ele é um personagem esquisito, como os alunos disseram, parece fazer sentido. Dois alunos fizeram juntos uma análise freudiana do filme, dizendo que Lourenço ficou preso em sua fase anal, por ser obcecado pela região traseira do corpo de uma personagem e por ser "perseguido" pelo cheiro do ralo do banheiro. Assim como essa, muitas outras análises psicanalíticas poderiam, de fato, ser feitas. No entanto, o nojo pelo personagem, a aversão pela perversidade que ele manifesta - tudo isso parece ter impedido os alunos de pensarem mais sobre o filme, assumindo quase um ódio em relação à narrativa, por verem ali sentimentos tão maldosos e pelo fato de o filme despertar sensações de nojo, tristeza, infelicidade.

"O Cheiro do Ralo" não oferece nenhuma redenção aos personagens, nem ao espectador, jogado em cenas violentas, repugnantes, agressivas e de difícil compreensão. Não há uma lógica fácil a ser aplicada ao filme. Ninguém se comporta de forma previsível. Tais elementos da construção narrativa foram os que, justamente, pareceram desestabilizar os alunos e motivar diferentes comentários, os quais enriqueceram em muito as discussões de sala de aula. Assim, chamou a atenção dos estudantes o fato de os personagens parecerem egoístas, em especial, claro, Lourenço e sua vontade de comprar, mandar no outro e humilhá-lo. "O Cheiro do Ralo" não seria, nesse sentido, um filme "belo", de acordo com o que parece ser a compreensão manifestada pelos alunos em seus julgamentos. Em sua maioria, os estudantes ficaram tão "revoltados" com Lourenço que tiveram até dificuldade de falar sobre a narrativa. Talvez eles tenham sentido uma espécie de desilusão, uma quebra na crença nos sentimentos de amor e esperança, tais como os que os filmes de Walter Salles haviam trazido.

(c) ETD-Educação Temática Digital Campinas, SP v.19 n.2 $\quad$ p. 316-337 abr./jun. 2017 
Justamente por se tratar de uma pesquisa do campo da educação, pensamos também em como, no papel de educadores, trabalhamos em sala de aula com os filmes, e ainda, como lidamos com os comentários dos alunos para ajudá-los a produzir pensamento sobre imagem, narrativa e alteridade. Perguntamos, aqui, novamente: como trabalhamos uma educação do olhar mediada pelo cinema e pela alteridade? As preciosas sugestões de Alain Bergala, em "L'Hypothèse Cinema", sobre as experiências com filmes, em ambiente educacional, ressaltam a importância da seleção do que será exibido, no sentido de privilegiar as narrativas que "queimam", que deixam lacunas, que permitam ao espectador "respirar" - justamente porque naquele filme há uma vida que pulsa, que ali transborda. Ora, se havemos de cuidar das nossas escolhas, também somos convocados a um trabalho, com crianças e jovens, um trabalho feito com tal cuidado, que permita uma ampliação dos modos de ver. Isso significa, entre outras coisas, uma exploração das próprias manifestações dos alunos diante das películas, a começar pela rejeição aos modos "bem-pensantes" de um espectador que rapidamente classifica e rotula o que viu. Isso corresponde, também, à opção por filmes cujos diretores não quiseram meramente "traduzir" uma ideia prévia, não tinham uma resposta antecipada, ideologicamente correta. Seu filme "pensa" na medida em que está sendo filmado. Em outras palavras: sem desqualificar o que nossos alunos nos diziam, procurávamos polemizar, interrogar. E aprender sobre a experiência de um espectador estrangeiro.

De qualquer forma, o que foi relatado aqui, sobre a experiência dos alunos em sala de aula, pode talvez ser pensado como uma "vontade catártica" diante do cinema, ou seja, sobre o desejo de que os personagens vivam certos sentimentos e situações tais como aqueles que gostaríamos também de viver. Gostamos de "Abril Despedaçado" porque não há como não admirar Menino e seu jeito poético de viver e falar, seu amor pelo irmão que o levou a sacrificar sua própria vida. Queremos acreditar nesse sentimento, desejamos, esse sentimento. Não gostamos de "O Cheiro do Ralo" porque não aceitamos alguém como Lourenço em nossas vidas. Lourenço nos provoca repulsa, nos assusta, talvez nos faça pensar sobre a possibilidade de termos pessoas como ele à nossa volta, ou, pior ainda, de (quem sabe?) sermos um pouco perversos como ele. Esse, certamente, não é um pensamento confortável.

Não pretendemos aqui separar os filmes de Walter Salles como pacíficos e de bons sentimentos, e o filme de Heitor Dahlia como confrontador e desprezível. Ambos são feitos de profundas dores, complexidades e intensidades - cada um a seu modo. O que destacamos (e que nos fez pensar) foram as qualificações e as avaliações dos estudantes estrangeiros: em "Central do Brasil" e "Abril Despedaçado", eles viram beleza, amor e esperança; em "O Cheiro do Ralo", viram-se diante de agressividade, violência e imagens 
plenamente desconfortáveis. Em todos os grupos, nos dois anos de pesquisa e de aulas, os filmes de Walter Salles foram os que mais agradaram.

\section{CONTRA A AMPUTAÇÃO DA ALTERIDADE}

Como dissemos na introdução a este texto, a experiência com o cinema brasileiro, visto pelos estudantes estrangeiros, nos conduziu a buscar em autores como Deleuze, Nietzsche e Julia Kristeva - entre outros - um modo de pensar sobre os dados registrados na pesquisa. De um lado, nosso propósito consistiu em ir além das dualidades que separam aparência de verdade, belo e feio, bondade de maldade. Nos estudos de Nietzsche, encontramos apoio para depositar um olhar talvez mais problematizador, sobre as manifestações dos nossos alunos. Assim, pudemos pensar como, diante dos filmes selecionados para análise, os estudantes apontaram, nas narrativas de Salles, o que thes sobressaiu como belo e bom, praticamente apagando toda a dureza de vidas como as de Josué, Dora e Menino, por exemplo. Ou seja: a complexidade daquelas existências foi reduzida, amputada, apagando-se a riqueza de figuras que poderiam nos mostrar o outro, a radicalidade de um outro que, como escreve Julia Kristeva, não está tranquilamente fora de nós; pelo contrário, um outro que também somos nós.

Como se só interessasse um mundo apolineamente construído, cortavam-se as arestas da dor e do sofrimento, negava-se a "realidade violenta" e desenhava-se um mundo de bons sentimentos. Mesmo em meio à pobreza e às tristezas daquelas vidas, nos filmes de Salles, elegia-se um culto à beleza, às aparências perfeitas, ao quase divino (em Josué, Dora, Tonho e Menino - e em nós mesmos). Estava então garantida a possibilidade de sobreviver às agruras da existência. Estava garantida a mesmidade. Quanto ao filme de Dahlia, predominou o que Deleuze escreve sobre o ato de "julgar a vida", exigir-lhe um valor superior, apontando - como o fizeram os estudantes - aquilo que vai mal, aquilo que não é da ordem do "bem", a noção de verdade como sendo predominantemente da ordem da moral. Ora, estava em jogo aí um modo de classificar o outro - no caso, a partir do personagem Lourenço, o outro-Brasil, confirmado e sintetizado naquele que "amava o ralo", o outro da violência e da miséria, como se isso fosse privilégio deste País, e como se não houvesse também em cada um de nós um lado obscuro, e por vezes, assustador.

A positividade do falso, tal como a defende Deleuze, estaria diretamente relacionada à criação, à invenção das artes (como a do cinema), em que deixamos de lado uma certa moralidade da verdade e até a própria vontade, tão exacerbada, de verdade em tudo o que vemos e dizemos. A positividade do falso seria vital, para o filósofo, no sentido de que sobrepõe a tudo o poder transfigurador da arte, para além do bem e do mal, para além da dicotomização da vida. Nessa perspectiva, o que é narrado num filme não nos conduziria

\section{(C) ETD-Educação Temática Digital Campinas, SP v.19 n.2 p. $316-337$ abr./jun. 2017}


necessariamente a exigir-lhe "verdade" comprovada, tampouco clareza e separação entre possíveis e impossíveis nas cenas e personagens. O que se oferece na arte seriam alternativas sem possibilidade de distinguir com perfeita nitidez o que é real, o que é da ordem do imaginário. O falso, no cinema, seria justamente aquilo que nos fala da mais genuína transformação, para além de qualquer pretensão à verdade ou à aparência agradável ou indesejada, por sua "beleza" ou sua "feiura" (MACHADO, p. 285 e seguintes).

Talvez o caminho de investigação seja aquele que propõe uma fuga dessas dicotomias, um escape, uma possibilidade de produção criativa, assim como a vontade de potência de Nietzsche. Precisamos "fazer a curva", pensar a dobra. Talvez seja esse o maior desafio do estudo de cinema na educação, especialmente considerando essa experiência radical com alteridade da qual se trata o contexto específico deste trabalho. Revendo o material empírico desta pesquisa, encontramos ainda muitos textos de alunos com o título "A violência nos filmes brasileiros"; mesmo com a diversidade de filmes vistos, parece, muitas vezes, permanecer uma barreira diante do outro. A alteridade é um constante desafio, para os alunos e professores, e acreditamos que o cinema coloca em funcionamento esse desafio, complexifica-o, talvez possibilite, então, uma curva, uma dobra.

Não podemos, certamente, negar a importância para os alunos, ao ressaltarem os sentimentos belos dos filmes de Walter Salles:

Da: Depois de ele matou o inimigo, ele sabia que só teve pouco tempo que lhe restava para viver. Por isso, o seu abril foi despedaçado em dois: antes, quando matou o inimigo da família, foi o segurança, depois, o fugitivo.

Na: Eu assisti "Abril Despedaçado" duas vezes. Cada uma tem sentimentos diferentes. A história me produz uma profunda impressão. No momento em que Tonho sai de casa e consegue derrubar as barreiras, ele começa a se transformar sua visão de mundo. Ele tem amor verdadeiro. Tonho deixa de ser objeto da ação dos outros.

O cinema estrangeiro, sem dúvidas, produziu algo nos alunos, algo que os fez escrever, debater. A repulsa, a incapacidade de falar sobre o ódio, por exemplo, diante do filme de Heitor Dahlia, tem uma relação profunda com os desafios da alteridade. Vejamos algumas respostas à pergunta "O que você tem a dizer sobre o cinema brasileiro?":

Ve: Em geral, não gosto muito por causa da cultura diferente, alguns filmes não são bonitos, é difícil entender.

Is: $O$ cinema brasileiro sempre tem acesso com relação de poder e política. Isso é um pouco difícil para nós estrangeiros. Mas é um desafio.

(c) ETD-Educação Temática Digital Campinas, SP v.19 n.2 $\quad$ p. 316-337 abr./jun. 2017 
Si: Eu acho que a maioria do filme brasileiro é um pouco estranho, sempre tem violência e falecimento.

Sa: Despois de assistir muitos filmes brasileiros, achei que além dos assuntos mais populares da sociedade brasileira, alguns filmes tratam de assuntos muito estranhos.

As respostas dessas alunas colocam em movimento conceitos importantes, relativos à complexa discussão sobre o tema da alteridade; as estudantes falam em desafio, em cultura, no diferente, naquilo que lhes é estranho.

Qualquer um de nós é, de alguma forma, um estrangeiro. Certos filmes, como vimos, não deixam essa relação com a alteridade "descansar"; não nos confortam jamais. O deslumbramento com o sentimento do belo ou do desprezível, merecedor do nosso ódio, bem como a dificuldade de entender e receber o estranho, o diferente, em suma, o "louco" - tudo isso esteve presente nas aulas e foi extremamente relevante para a pesquisa. Uma singela aula de cinema brasileiro para estrangeiros coloca em evidência a urgência do pensamento sobre o estrangeiro e a alteridade, justamente por acontecer ali o debate em que se evidenciam tantos pensamentos dicotômicos, tanta dificuldade de lidar com o inesperado, com aquilo de que "não gostavam", aquilo que para muitos deles era "tão diferente". Longe das dicotomias e das interpretações fáceis, por vezes moralizantes, numa forma de pensamento que, ao invés de ampliar-se, busca o rápido fechamento, entendemos que a atitude ética e estética é aquela que não procura fixar nem coisificar as estranhezas, como nos sugere Julia Kristeva. Até porque estranhezas nos pertencem; por vezes gaguejamos em nossa própria língua, nos diz Deleuze. Resta-nos ficar na própria criação, entregarmo-nos a ela, escaparmos à vontade de poder e verdade em relação ao outro a nosso lado, ao outro que não comunga nossas ideias nem nossas cotidianas vidas, ao outro forasteiro, ao outro desacomodador, ao outro que habita cada um de nós.

"Como se descolar do espelho?" - pergunta Roland Barthes no texto "Ao sair do cinema" (BARTHES, 2004, p. 432). Ele responde, num belo jogo de palavras: descolo-me do espelho, "decolando", rompendo a dualidade, a "hipnose da verossimilhança", distanciando-me brechtianamente do que vejo, e ao mesmo tempo deixando-me fascinar duplamente, pela imagem e pelo entorno, no sentido de "complicar" a situação, vivendo uma espécie de "distância amorosa". Pensar tais narrativas, assim, seria aceitar o desconhecido e o desconhecimento, nesse "festival de afetos que se chama um filme" (idem, p. 428).

(c) ETD-Educação Temática Digital Campinas, SP $\quad$ v.19 $\quad$ n.2 $\quad$ p. 316-337 abr./jun. 2017 
DOI: https://doi.org/10.20396/etd.v19i2.8647464

\section{REFERÊNCIAS}

BADIOU, Alain. El cine como experimentación filosófica. In: YOEL, Gerardo (Comp.). Pensar el cine 1. Imagen, ética y filosofia. Buenos Aires: Manantial, 2004. p. 23-81, p. 254. ISBN 987-500-082-5.

BARTHES, Roland. Ao sair do cinema. In: 0 rumor da língua. Trad. Mario Laranjeira. São Paulo, SP: Martins Fontes, 2004. p. 427-433. p. 462. ISBN: 85-336-1986-3.

BERGALA, Alain. La hipótesis del cine. Pequeño tratado sobre la transmisión del cine en la escuela y fuera de ella. Trad. Núria Aidelman; Laia Colell. Barcelona: Laertes, 2007. p. 206. ISBN: 978-847-584-607-1.

DELEUZE, Gilles. Imagem-tempo. São Paulo, SP: Brasiliense, 2007. p. 338.

ISBN: 85-11-22028-3

HILGERT, Ananda Vargas. Alteridade e experiência estética: o olhar, o outro, o cinema. Dissertação de Mestrado. PPGEDU/UFRGS. Rio Grande do Sul, 2014. p. 107.

KRISTEVA, Julia. Estrangeiros para nós mesmos. Rio de Janeiro, RJ: Rocco, 1994. p. 205.

MACHADO, Roberto. Nietzsche e a Verdade. São Paulo, SP: Paz e Terra, 1999. p. 110. ISBN: 85-7038-007-0

MACHADO, Roberto. Deleuze, a arte e a filosofia. Rio de Janeiro, RJ: Zahar, 2009. p. 344. ISBN: 978-8537-80165-9.

MARCELLO, Fabiana de Amorim. Criança e cinema no exercício estético da amizade. ProPosições, n. 3, v. 20 (60), p. 215-230, set. /dez. Campinas, SP, 2009.

NIETZSCHE, Friedrich. Além do bem e do mal. São Paulo, SP: Companhia das Letras, 2010. p. 246. ISBN: 978-85-359-0641-7

NIETZSCHE, Friedrich. A visão dionisíaca do mundo. São Paulo, SP: Martins Fontes, 2005. p. 94. ISBN 85-336-2204-X.

ROUDINESCO, Elisabeth. A parte obscura de nós mesmos. Rio de Janeiro, RJ: Zahar, 2008. p. 224. ISBN: 978-85-378-0081-2.

XAVIER, Ismail. O olhar e a cena. São Paulo, SP: Cosac \& Naify, 2003. p. 381.

ISBN: 85-7503-231-3. 
XAVIER, Ismail. Um cinema que "educa" é um cinema que (nos) faz pensar. Educação \& Realidade, n. 33 (1), p. 13-20, jan./jun, 2008. ISSN: 0100-3143. Entrevista.

FILMES CITADOS:

ABRIL DESPEDAÇADO. Walter Salles. Brasil: 2001. 105 min.

CENTRAL DO BRASIL. Walter Salles. Brasil: 1998. $112 \mathrm{~min}$.

EDIFÍCIO MASTER. Eduardo Coutinho. Brasil: 2002. $110 \mathrm{~min}$.

O CHEIRO DO RALO. Heitor Dhalia. Brasil: 2006. 112 min.

O INVASOR. Beto Brant. Brasil: 2002. 97 min.

O PALHAÇO. Selton Mello. Brasil: 2011. 88 min.

' Revisão gramatical do texto sob a responsabilidade: Rosa Maria Bueno Fischer e Ananda Vargas Hilgert.

(C) ETD-Educação Temática Digital Campinas, SP v.19 $\quad$ n.2 $\quad$ p. 316-337 abr./jun. 2017 